the latter a signed schedule,-the advantage of the professor and not the advancement of the student being the point considered. During the last few years a reaction has been setting in against this perpetual lecturing, and the number required to be attended has been considerably reduced. The University of London deserves the credit of having been the first to break through this absurd system, by requiring attendance on only one or two courses, and this rather as evidence of the student being really engaged in the study of medicine than for any other purpose, leaving him free to acquire his information as best he can, but testing its extent and value by a searching examination.

No doubt many of the posts above alluded to are filled by men of great talent and ability, but their powers are crippled by the small means at their disposal, which prevents many illustrations or experiments from being exhibited which are almost essential for thorough teaching.

As a means of improving the system of education by supplying a better class of lectures on some subjects than those at present given, and at the same time obtaining better remuneration for the lecturers themselves, a scheme has recently been advanced by which it is proposed that certain medical schools in the metropolis should be amalgamated, a reduction in the number of lecturers being thus effected, whilst the pecuniary value of those that remain will undergo considerable augmentation. It is hoped that the value of these posts would then be sufficient to lead to their being accepted not by those who only use them as a steppingstone for advancement, but by gentlemen who have devoted themselves exclusively to the study of the department of science on which they lecture.

At the present moment the lectureships in several of the smaller schools yield such small returns to their holders as would astonish many of their hearers. As a matter of fact we could mention an instance where the proceeds of an entire summer course of lectures has amounted on the average for the past three years to a sum not exceeding 6l. Can this for a moment be regarded as in any way proportionate to the intellectual labour, the time, and the money expended in their preparation, illustration, and delivery? It might be considered to be a moderate recompense for one lecture, but as payment for a course it is simply monstrous. Is it surprising that the lectures are often given without animation, and listened to without interest?

By amalgamating several schools, however, such chairs might, it is hoped, be so far increased in value as not only to lead men of high ability, and distinguished for their knowledge in particular branches of science, to accept them, but to provide ample funds to admit of their copious illustration, and for the purchase of expensive apparatus - apparatus which the smaller schools now find it difficult or impossible to procure. It would not be difficult, we imagine, to find room for those who at present hold appointments as demonstrators, with lighter but not less important duties than they have hitherto per$f$ ormed. At all events it seems to us that the amalgamation scheme, if fairly carried out, would prove the most splendid example of the Conservation of Force with which we are acquainted, and on that ground alone should receive the cordial support of the medical teachers through- out the metropolis. In a future article we shall suggest what appears to us a desirable and practical scheme for medical education.

\section{THE LITERATURE OF CHEMISTRY}

THE appearance of the April number of the "Journal 1 of the Chemical Society" marks the commencement of a new era in English Chemical Literature, containing, as it does, besides the papers which have been read before the Society, the first instalment of the promised "abstracts." The papers selected for this purpose by the accomplished editor are ninety-one in number, comprising every branch of Chemical Science, Technology included, and are classified under six various headings, as "Physical Chemistry," "Inorganic Chemistry," \&c. The abstracts themselves, made by the gentlemen whose names appear on the wrapper of the journal, are naturally of different degrees of literary merit, but seem to be carefully and conscientiously done; all the points of essential importance in the original papers being retained. The reader will thus not only have a good general notion of the extent of the researches made by any particular author, but also be able to repeat any of the experiments, or prepare any of the substances from the directions given. These abstracts are therefore really what they profess to be, and not merely notices of a few lines in length, from which but little more information can be gleaned than from the title of the paper.

The Council of the Chemical Society is to be congratulated on the energetic way in which it has endeavoured to supply a great defect in our scientific literature, by affording us the means of obtaining a general view of the progress of Chemistry both here and on the Continerit. Chemists have hitherto had to depend chiefly on Will's "Jahresbericht," which, although useful in its way, has the double disadvantage incident upon its method of arrangement, first, in not being published until long after the end of the year, and, secondly, of being rather a résumé of the chemical work done, than a condensed account of particular researches. There is no doubt that these abstracts, if furnished with a full and comprehensive index, both of the subject-matter and the names of the authors, will become a standard work of reference, not only here but on the Continent.

It is to be hoped that other Scientific Societies will be induced to follow the example of the Chemical Society, and, by publishing abstracts of all papers connected with their particular branch of science, give an impetus to its cultivation, and render a knowledge of its general progress easily attainable. The value of such abstracts is greater than might at first sight appear ; for the study of Science, both for its own sake, and in its application to the Arts, is extending so rapidly that it requires a considerable expenditure of time to acquire a knowledge of the numerous researches and discoveries which are now being made in any particular science, and leaves but little for the study of the sciences allied to it. If, then, each of the learned societies were to publish abstracts similar to those of the Chemical Society, it would render it comparatively easy for the workers in any one department of science to acquire something more than a superficial knowledge of the discoveries made in the others. 